\title{
Optimal Monetary Policy in a Small Open Economy with Home Bias
}

\author{
Ester Faia \\ Universitat Pompeu Fabra
}

\author{
Tommaso Monacelli* \\ IGIER, Università Bocconi and CEPR
}

January 2006

\begin{abstract}
We analyze optimal monetary policy in a small open economy characterized by home bias in consumption. Peculiar to our framework is the application of a Ramsey-type analysis to a model of the recent open economy New Keynesian literature. We show that home bias in consumption is a sufficient condition for inducing monetary policy-makers of an open economy to deviate from a strategy of strict markup stabilization and contemplate some (optimal) degree of exchange rate stabilization. We focus on the optimal setting of policy both in the case in which firms set prices one period in advance as well as in the case in which firms set prices in a dynamic forward-looking fashion. While the first setup allows us to analytically highlight home bias as an independent source of equilibrium markup variability, the second setup allows to study the effects of future expectations on the optimal policy problem and the effect of home bias on optimal inflation volatility. The latter, in particular, is shown to be related to the degree of trade openness in a U-shaped fashion, whereas exchange rate volatility is monotonically decreasing in openness.
\end{abstract}

Keywords. Optimal Monetary Policy, Ramsey Planner, Home Bias, Sticky Prices.

JEL Classification Number: E52, F41.

\footnotetext{
${ }^{*}$ Correspondence to IGIER Universita' Bocconi, Via Salasco 3/5, 20136 Milan, Italy. Email: tommaso.monacelli@uni-bocconi.it, Tel: +39-02-58363330, Fax: +39-02-58363332, Web page: www.igier.unibocconi.it/monacelli.
} 


\section{Introduction}

The issue of whether exchange rate stabilization should be part of a central bank's monetary policy strategy, and more generally of whether the optimal setting of policy in an open economy bears fundamental differences with respect to a closed economy, are at the heart of the recent developments of the open economy New Keynesian literature. ${ }^{1}$

This paper studies optimal monetary policy in a small open economy characterized by home bias in consumption. In our context, the presence of home bias is the key factor generating endogenous real exchange rate fluctuations. Hence, despite the fact that, in the absence of any impediment to trade, the law of one price holds continually at the level of each individual good, equilibrium deviations from PPP are feasible. In addition, our economy features goods markets characterized by imperfect competition and nominal rigidities, and complete markets for internationally traded state contingent securities.

We do not attempt to provide a theory of home bias in this context, but rather we model it as a primitive feature of our economic environment. Importantly, the presence of home bias in consumption is a fundamental characteristic of international trade data. For instance, Obstfeld and Rogoff (2003) list home bias in trade as one of the six major puzzles in international macroeconomics. Our interest here is in studying the effects of home bias on the optimal setting of monetary and exchange rate policy.

We study monetary policy both in the case in which firms set prices one period in advance as well as in the case in which prices are set in a forward-looking fashion. While the former static setup permits an analytical inspection of the main forces that drive the behavior of markups under the optimal policy, the latter setup (intrinsically dynamic) allows to study the impact of future expectations on the optimal policy problem and in particular on the equilibrium volatility of inflation.

Our analysis makes two main contributions. First, we highlight that home bias in consumption is an independent condition inducing monetary policy makers of an open economy to deviate from an inward-looking strategy of strict markup stabilization, and thus contemplate some (optimal) degree of exchange rate stabilization. This differs from the popular Friedman (1956) prescription, derived for instance in Devereux and Engel (2003), according to which, in the presence of price stickiness,

\footnotetext{
${ }^{1}$ The so-called New Open Economy Macroeconomics literature has grown rapidly in the last few years. See for instance Obsteld and Rogoff (1996), Benigno and Benigno (2003), McCallum and Nelson (2000), Corsetti and Pesenti (2001, 2003), Kollman (2002), Devereux and Engel (2003), Clarida, Galí, and Gertler (2002), Pappa (2003).
} 
exchange rate movements should be instrumental to have the economy replicate the allocation under purely flexible prices. Intuitively, with price stickiness and in response to asymmetric shocks, the planner of a small economy would like to engineer an optimal adjustment of the whole range of relative prices that affect the consumer's purchasing power. In the absence of home bias (i.e., with PPP holding), this requires inducing terms of trade adjustments that allow to strike an optimal balance between markup smoothing and preservation of households' purchasing power. Other contributions (such as Corsetti and Pesenti (2001), Sutherland (2002) and Benigno and Benigno (2003)) have shown that this terms of trade motive for optimal markup variability depends on the underlying specification of the utility function (e.g., it vanishes in the case of unitary intratemporal trade elasticity). This paper suggests that, in the presence of home bias and even in the case in which preferences may inhibit the terms of trade motive, a complementary real exchange motive emerges in general to induce variable markups under the optimal allocation.

Our second contribution has a more methodological flavor. We suggest that optimal monetary policy in a small open economy can be usefully characterized by applying a Ramsey-type analysis. In the classic approach to the study of optimal policy in dynamic economies (Ramsey (1927), Atkinson and Stiglitz (1976), Lucas and Stokey (1983), Chari, Christiano and Kehoe (1991)), and in a typical public finance spirit, a Ramsey planner maximizes household's welfare subject to a resource constraint, to the constraints describing the equilibrium in the private sector economy, and via an explicit consideration of all the distortions that characterize both the long-run and the cyclical behavior of the economy. Recently there has been a resurgence of interest for a Ramseytype approach in dynamic general equilibrium models with monopolistic competition and nominal rigidities. Examples include, in the context of closed economy models, Adao et al. (2003), Khan, King and Wolman (2003), Schmitt-Grohe and Uribe (2004) and Siu (2004). ${ }^{2}$ However, most of the welfare analysis of monetary policy in the recent literature builds on a linear-quadratic approximation approach in the spirit of Rotemberg and Woodford (1997), Woodford (2003) and Benigno and Woodford (2004). A Ramsey-type approach has featured even more limited applications to the recent growing literature of New Keynesian open economy models. ${ }^{3}$

The remainder of the paper is as follows. Section 2 describes the economic environment.

\footnotetext{
${ }^{2}$ Schmitt-Grohe and Uribe (2004) and Siu (2004), in particular, analyze the more general issue of the optimal joint determination of monetary and fiscal policy.

${ }^{3}$ For an application of a Ramsey-type analysis in the context of a two-country model, see, under sticky prices, Faia and Monacelli (2003), and, under flexible prices, Arsenau (2004). For applications employing a so-called linearquadratic approach, see Benigno and Benigno (2004) and De Paoli (2004).
} 
Section 3 illustrates the details of the optimal monetary policy problem under preset prices. Section 4 extends the analysis to forward-looking price setting. Section 5 concludes.

\section{The Model}

The world economy consists of two economic entities, a small economy and a rest of the world. Preferences feature home bias in consumption. Each economy is populated by infinitely-lived agents. The total measure of the world economy is normalized to unity, with Home and Foreign having measure $n$ and $(1-n)$ respectively. To characterize the small economy case we resort to a "limit-case" approach, as in Galí and Monacelli (2002), Sutherland (2005), De Fiore and Liu (2005) and De Paoli (2004). This consists in characterizing the domestic economy as small in size relative to the rest of the world, whose equilibrium dynamics are akin to the one of a standard closed economy.

\subsection{Domestic Households}

Consumption preferences in the Home economy are described by the following composite index of domestic and imported bundles of goods:

$$
C_{t} \equiv\left[(1-\gamma)^{\frac{1}{\eta}} C_{H, t}^{\frac{\eta-1}{\eta}}+\gamma^{\frac{1}{\eta}} C_{F, t}^{\frac{\eta-1}{\eta}}\right]^{\frac{\eta}{\eta-1}}
$$

where $\eta>0$ is the elasticity of substitution between domestic and foreign goods, and $\gamma \equiv(1-n) \alpha$ denotes the weight of imported goods in Home consumption basket. This weight depends on $(1-n)$, the relative size of Foreign, and on $\alpha$, the degree of trade openness of Home. In an analogous manner, preferences in Foreign can be described as:

$$
C_{t}^{*} \equiv\left[\left(1-\gamma^{*}\right)^{\frac{1}{\eta}} C_{F, t}^{* \frac{\eta-1}{\eta}}+\left(\gamma^{*}\right)^{\frac{1}{\eta}} C_{H, t}^{* \frac{\eta-1}{\eta}}\right]^{\frac{\eta}{\eta-1}}
$$

where $\gamma^{*} \equiv n \alpha^{*}$ We assume home bias in consumption, which entails:

$$
1-(1-n) \alpha>n \alpha^{*}
$$

Notice that in the symmetric case of $\alpha=\alpha^{*}$ (and regardless of the relative size assumption), as well as in the limiting case $n \rightarrow 0$, home bias requires $\alpha<1$. The same argument holds exactly for consumption preferences in Foreign. ${ }^{4}$

\footnotetext{
${ }^{4}$ Home bias in Foreign preferences requires
} 
Each consumption bundle $C_{H, t}$ and $C_{F, t}$ is composed of imperfectly substitutable varieties (with elasticity of substitution $\varepsilon>1$ ). Optimal allocation of expenditure within each variety of goods yields:

$$
C_{H, t}(i)=\frac{1}{n}\left(\frac{P_{H, t}(i)}{P_{H, t}}\right)^{-\varepsilon} C_{H, t} \quad ; \quad C_{F, t}(i)=\frac{1}{1-n}\left(\frac{P_{F, t}(i)}{P_{F, t}}\right)^{-\varepsilon} C_{F, t}
$$

where $C_{H, t} \equiv\left(\frac{1}{n}\right)^{\frac{1}{\varepsilon}} \int_{0}^{n}\left[C_{H, t}(i)^{\frac{\varepsilon-1}{\varepsilon}} d i\right]^{\frac{\varepsilon}{\varepsilon-1}}$ and $C_{F, t} \equiv\left(\frac{1}{1-n}\right)^{\frac{1}{\varepsilon}} \int_{n}^{1}\left[C_{F, t}(i)^{\frac{\varepsilon-1}{\varepsilon}} d i\right]^{\frac{\varepsilon}{\varepsilon-1}}$.

Optimal allocation of expenditure between domestic and foreign bundles yields:

$$
C_{H, t}=(1-\gamma)\left(\frac{P_{H, t}}{P_{t}}\right)^{-\eta} C_{t} ; C_{F, t}=\gamma\left(\frac{P_{F, t}}{P_{t}}\right)^{-\eta} C_{t}
$$

where

$$
P_{t} \equiv\left[(1-\gamma) P_{H, t}^{1-\eta}+\gamma P_{F, t}^{1-\eta}\right]^{\frac{1}{1-\eta}}
$$

is the CPI index.

We assume, both within and across countries, the existence of complete markets for statecontingent claims expressed in units of domestic currency. Let $h^{t}=\left\{h_{0}, \ldots . h_{t}\right\}$ denote the history of events up to date $t$, where $h_{t}$ is the event realization at date $t$. The date 0 probability of observing history $h^{t}$ is given by $\rho\left(h^{t}\right)$. The initial state $h^{0}$ is given so that $\rho\left(h^{0}\right)=1$.

Agents maximize the following expected discounted sum of utilities over possible paths of consumption and labor:

$$
E_{0}\left\{\sum_{t=0}^{\infty} \beta^{t} U\left(C_{t}, N_{t}\right)\right\}
$$

where $E_{0}\{\}$ denotes the mathematical expectations operator conditional on $h_{0}$ and $N_{t}$ is labor hours. ${ }^{5}$ The function $U(\bullet)$ features typical regularity conditions and is assumed to be separable in

$$
\left(1-\gamma^{*}\right)>\gamma
$$

This implies

$$
(1-\alpha)>n\left(\alpha-\alpha^{*}\right)
$$

which can be rewritten as (3).

${ }^{5}$ Hence the expression for lifetime utility is equivalent to writing

$$
\sum_{t=0}^{\infty} \sum_{h^{t}} \beta^{t} U\left(C\left(h^{t}\right), N\left(h^{t}\right)\right) \rho\left(h^{t}\right)
$$

where $\rho\left(h^{t}\right)=\rho\left(h_{t} \mid h_{0}\right)$. 
its arguments. To insure their consumption pattern against random shocks at time $t$ households spend $\nu_{t+1, t} B_{t+1}$ in nominal state contingent securities where $\nu_{t, t+1} \equiv \nu\left(h^{t+1} \mid h^{t}\right)$ is the period- $t$ price of a claim to one unit of currency in state $h^{t+1}$ divided by the probability of occurrence of that state. Each asset in the portfolio $B_{t+1}$ pays one unit of domestic currency at time $t+1$ and in state $h^{t+1}$.

By considering the optimal expenditure conditions (4) and (5), the sequence of budget constraints assumes the following form:

$$
P_{t} C_{t}+\sum_{h^{t+1}} \nu_{t+1, t} B_{t+1} \leq W_{t} N_{t}+\tau_{t}+B_{t}+\int_{0}^{1} \Gamma_{t}(i)
$$

where $\tau_{t}$ are government net transfers of domestic currency and $\Gamma_{t}(i)$ are the profits of monopolistic firm $i$, whose shares are owned by the domestic residents. ${ }^{6}$ The representative household chooses processes $\left\{C_{t}, N_{t}\right\}_{t=0}^{\infty}$ and bonds $\left\{B_{t+1}\right\}_{t=0}^{\infty}$ taking as given the set of processes $\left\{P_{t}, W_{t}, \nu_{t+1, t}\right\}_{t=0}^{\infty}$ and the initial wealth $B_{0}$ so as to maximize (7) subject to (8).

For any given state of the world, the following set of efficiency conditions must hold:

$$
\begin{gathered}
U_{c, t} \frac{W_{t}}{P_{t}}=-U_{n, t} \\
\beta \frac{P_{t}}{P_{t+1}} \frac{U_{c, t+1}}{U_{c, t}}=\nu_{t, t+1} \\
\lim _{j \rightarrow \infty} E_{t}\left\{\nu_{t, t+j} B_{t+j}\right\}=0
\end{gathered}
$$

where $U_{j, t}$ defines the first order derivative of utility with respect to its argument $j=C, N$. Equation (9) equates the CPI-based real wage to the marginal rate of substitution between consumption and leisure. Equation (12) describes a set of optimality conditions for each possible state $h^{t+1}$. Optimality requires that the first order conditions (9), (10) and the no-Ponzi game condition (11) are simultaneously satisfied.

Taking conditional expectations of equation (12) allows to define a gross nominal interest rate (or return on the corresponding riskless one-period bond) as:

$$
\begin{aligned}
R_{t} & \equiv E_{t}\left\{\nu_{t+1, t}\right\}^{-1} \\
& =\left[\beta E_{t}\left\{\frac{P_{t}}{P_{t+1}} \frac{U_{c, t+1}}{U_{c, t}}\right\}\right]^{-1}
\end{aligned}
$$

\footnotetext{
${ }^{6}$ Each domestic household owns an equal share of the domestic monopolistic firms. We abstract from international trade in shares.
} 
which is a familiar consumption Euler equation. Notice that, following large part of the recent literature, we do not introduce money explicitly, but rather think of it as playing the role of nominal unit of account. ${ }^{7}$

\subsection{Law of One Price, Foreign Demand, Terms of Trade and the Real Exchange Rate}

We assume throughout that the law of one price holds, implying that $P_{F, t}(i)=\mathcal{E}_{t} P_{F, t}^{*}(i)$ for all $i \in[0,1]$, where $\mathcal{E}_{t}$ is the nominal exchange rate, i.e., the price of foreign currency in terms of home currency, and $P_{F, t}^{*}(i)$ is the price of foreign good $i$ denominated in foreign currency. Notice that the holding of the law of one price does not necessarily imply that PPP holds, unless we make the further restrictive assumption of absence of home bias.

Foreign demand for domestic variety $i$ must satisfy:

$$
\begin{aligned}
C_{H, t}^{*}(i) & =\frac{1}{n}\left(\frac{P_{H, t}^{*}(i)}{P_{H, t}^{*}}\right)^{-\varepsilon} C_{H, t}^{*} \\
& =\frac{1}{n}\left(\frac{P_{H, t}^{*}(i)}{P_{H, t}^{*}}\right)^{-\varepsilon} \gamma^{*}\left(\frac{P_{H, t}^{*}}{P_{t}^{*}}\right)^{-\eta} C_{t}^{*}
\end{aligned}
$$

The terms of trade is the relative price of imported goods:

$$
S_{t} \equiv \frac{P_{F, t}}{P_{H, t}}
$$

while the real exchange rate is defined as $Q_{t} \equiv \frac{\mathcal{E}_{t} P_{t}^{*}}{P_{t}}$. The terms of trade can be related to the CPI-PPI ratio as follows

$$
\frac{P_{t}}{P_{H, t}}=\left[(1-\alpha)+\alpha S_{t}^{1-\eta}\right]^{\frac{1}{1-\eta}} \equiv g\left(S_{t}\right)
$$

with $g^{\prime}\left(S_{t}\right)>0$.

Notice that the terms of trade and the real exchange rate are linked through the following expression:

\footnotetext{
${ }^{7}$ See Woodford (2003), chapter 3. Thus the present model may be viewed as approximating the limiting case of a money-in-the-utility model in which the weight of real balances in the utility function is arbitrarily close to zero.
} 


$$
\begin{aligned}
Q_{t} & =S_{t} \frac{P_{t}^{*}}{P_{F, t}^{*}}\left(\frac{P_{t}}{P_{H, t}}\right)^{-1} \\
& =S_{t} \frac{g^{*}\left(S_{t}\right)}{g\left(S_{t}\right)} \equiv q\left(S_{t}\right)
\end{aligned}
$$

where

$$
\frac{P_{t}^{*}}{P_{F, t}^{*}}=\left[\left(1-\alpha^{*}\right)+\alpha^{*} S_{t}^{\eta-1}\right]^{\frac{1}{1-\eta}} \equiv g^{*}\left(S_{t}\right)
$$

with $q^{\prime}\left(S_{t}\right)>0$ and $g^{*^{\prime}}\left(S_{t}\right)<0$.

\section{$2.3 \quad$ Risk-Sharing}

Under complete markets for state contingent assets, the efficiency condition for bonds' holdings by residents in Foreign reads:

$$
\beta \frac{P_{t}^{*} \mathcal{E}_{t}}{P_{t+1}^{*} \mathcal{E}_{t+1}} \frac{U_{c, t+1}^{*}}{U_{c, t}^{*}}=\nu_{t, t+1}
$$

Taking conditional expectations of (18) and defining $R_{t}^{*} \equiv\left(E_{t}\left\{\nu_{t, t+1} \frac{\mathcal{E}_{t+1}}{\mathcal{E}_{t}}\right\}\right)^{-1}$ one can write:

$$
R_{t}^{*}=\left[\beta E_{t}\left\{\frac{P_{t}^{*}}{P_{t+1}^{*}} \frac{U_{c, t+1}^{*}}{U_{c, t}^{*}}\right\}\right]^{-1}
$$

Equating (10) with (18) and iterating yields the following condition linking the real exchange rate to the ratio of the marginal utilities of consumption across countries:

$$
\kappa \frac{U_{c, t}^{*}}{U_{c, t}}=\frac{\mathcal{E}_{t} P_{t}^{*}}{P_{t}} \equiv Q_{t}=q\left(S_{t}\right)
$$

where $\kappa \equiv \frac{\mathcal{E}_{0} P_{0}^{*} U_{c, 0}}{P_{0} U_{c, 0}^{*}}$. In the following we assume that the initial distribution of wealth is implemented in such a way that $\kappa=1$. Equation (20) is a typical condition that emerges in the presence of international asset markets where households engage in risk-sharing via the trading of state contingent securities. ${ }^{8}$.

\footnotetext{
${ }^{8}$ It is easy to show that if the risk-sharing trading of assets at time zero corresponds to the two agents equalizing their respective intertemporal budget constraint, necessarily $\kappa=1$ (see Devereux and Engel (2003), Faia and Monacelli (2004)). As a consequence of complete markets, whether the same asset trading is undertaken at time zero or sequentially is irrelevant for the specification of the equilibrium.
} 


\subsection{Production and Price Setting}

Each monopolistic firm $i$ produces a homogenous good according to the production function:

$$
Y_{t}(i)=A_{t} F\left(N_{t}(i)\right)
$$

where $A_{t}$ is a labor productivity shifter (common across firms) and $F(\bullet$ ) is a homogeneous function with $F_{n, t} \equiv \frac{\partial F}{\partial N_{t}}>0$. The cost minimizing choice of labor input implies:

$$
\frac{W_{t}}{P_{H, t}(i)}=\frac{M C_{t}}{P_{H, t}(i)} A_{t}
$$

where $M C$ denotes the nominal marginal cost. Notice that since households supply a homogenous type of labor the nominal wage and the marginal cost are common across firms.

We assume that prices are determined one period in advance. There is no international price discrimination. Each producer chooses the same price $P_{H, t}(i)$ to satisfy local and foreign demand and to maximize expected discounted nominal profits:

$$
E_{t-1}\left\{\nu_{t-1, t}\left[P_{H, t}(i) Y_{t}(i)-W_{t} N_{t}(i)\right]\right\}
$$

subject to

$$
Y_{t}(i) \leq\left(\frac{P_{H, t}(i)}{P_{H, t}}\right)^{-\varepsilon} Y_{t}
$$

and $(21)$, where $Y_{t}(i)$ is total demand for variety $i$ and $Y_{t}$ is world aggregate demand. By using (23) and (21) we can rewrite the profit function:

$$
\Gamma_{t}(i)=\left\{\nu_{t-1, t}\left[\left(\frac{P_{H, t}(i)}{P_{H, t}}\right)^{1-\varepsilon} P_{H, t} Y_{t}-W_{t} h\left(\left(\frac{P_{H, t}(i)}{P_{H, t}}\right)^{-\varepsilon} \frac{Y_{t}}{A_{t}}\right)\right]\right\}
$$

where $\left.h(\bullet) \equiv F^{-1}\left(\frac{Y_{t}(i)}{A_{t}}\right)=F^{-1}\left(P_{H, t}(i) ; P_{H, t}, A_{t}, Y_{t}\right)\right)=N_{t}(i)$.

The FOC with respect to $P_{H, t}(i)$ reads:

$$
E_{t-1}\left\{\nu_{t-1, t}\left[(1-\varepsilon)\left(\frac{P_{H, t}(i)}{P_{H, t}}\right)^{-\varepsilon} Y_{t}+\varepsilon \frac{W_{t}}{P_{H, t}} h^{\prime}(\bullet)\left(\frac{P_{H, t}(i)}{P_{H, t}}\right)^{-\varepsilon-1} \frac{Y_{t}}{A_{t}}\right]\right\}=0
$$

Notice that, in the case of linear technology $Y_{t}(i)=A_{t} N_{t}(i)$, we have $h^{\prime}(\bullet)=1$. In general, recall that $\frac{\partial h}{\partial P_{H, t}(i)}=\left(\frac{\partial F}{\partial h}\right)^{-1}=\left(\frac{\partial F}{\partial N_{t}(i)}\right)^{-1}$. 
Dividing through by $\left(\frac{P_{H, t}(i)}{P_{H, t}}\right)^{-\varepsilon}$, writing the product wage as $\frac{W_{t}}{P_{H, t}}=\frac{W_{t}}{P_{t}} g\left(S_{t}\right)$ and using (10) we obtain:

$$
\frac{\beta P_{t-1}}{U_{c, t-1}} E_{t-1}\left\{\frac{U_{c, t} Y_{t}}{P_{t}}\left[\frac{P_{H, t}(i)}{P_{H, t}}-\frac{\frac{W_{t}}{P_{t}} g\left(S_{t}\right)}{A_{t} F_{n, t}(i)} \frac{\varepsilon}{\varepsilon-1}\right]\right\}=0
$$

\subsection{Symmetric Equilibrium in a Small Open Economy}

Market clearing for domestic variety $i$ must satisfy:

$$
\begin{aligned}
Y_{t}(i) & =n C_{H, t}(i)+(1-n) C_{H, t}^{*}(i) \\
& =\left(\frac{P_{H, t}(i)}{P_{H, t}}\right)^{-\varepsilon}\left[(1-\gamma)\left(\frac{P_{H, t}}{P_{t}}\right)^{-\eta} C_{t}+\frac{(1-n)}{n} \gamma^{*}\left(\frac{P_{H, t}^{*}}{P_{t}^{*}}\right)^{-\eta} C_{t}^{*}\right] \\
& =\left(\frac{P_{H, t}(i)}{P_{H, t}}\right)^{-\varepsilon}\left[(1-(1-n) \alpha)\left(\frac{P_{H, t}}{P_{t}}\right)^{-\eta} C_{t}+(1-n) \alpha^{*}\left(\frac{P_{H, t}}{\mathcal{E}_{t} P_{t}^{*}}\right)^{-\eta} C_{t}^{*}\right]
\end{aligned}
$$

In a symmetric equilibrium, each domestic producer charges the same price and produces the same level of output, so that $P_{H, t}(i)=P_{H, t}, N_{t}(i)=N_{t}$ and $Y_{t}(i)=Y_{t}$ for all $i$.

Next, we restrict our attention to the limiting case of a small economy. This implies that the relative size of Home is negligible relative to the rest of the world, i.e., $n \rightarrow 0$. In this case, Foreign is an aggregate economy whose equilibrium dynamics is exogenous from the viewpoint of the small economy and approximately closed to trade. Notice that this assumption further implies $P_{F, t}^{*}=P_{t}^{*}$, which in turn implies $g^{*}\left(S_{t}\right)=1$. Hence, from (16), we have the following expression for the real exchange rate:

$$
q\left(S_{t}\right)=\frac{S_{t}}{g\left(S_{t}\right)}
$$

We further assume symmetric degree of home bias across countries, which requires $\alpha=\alpha^{*}$. Hence we can finally write:

$$
\begin{aligned}
Y_{t} & =g\left(S_{t}\right)^{\eta}\left[(1-\alpha) C_{t}+\alpha Q_{t}^{\eta} C_{t}^{*}\right] \\
& =(1-\alpha) g\left(S_{t}\right)^{\eta} C_{t}+\alpha S_{t}^{\eta} C_{t}^{*}
\end{aligned}
$$


Notice that in the particular case of absence of home bias, in which PPP holds at all times, we have $C_{t}=C_{t}^{*}$ and therefore $Q_{t}=1$ for all t. This implies $S_{t}=g\left(S_{t}\right)$ for all t. In this case, the market clearing condition (28) simplifies to:

$$
Y_{t}=g\left(S_{t}\right)^{\eta} C_{t}
$$

In equilibrium, and using (9) to replace the real wage, the price setting condition can be written

$$
E_{t-1}\left\{\left[\frac{A_{t} F\left(N_{t}\right) U_{c, t}}{g\left(S_{t}\right)}+\mu \frac{U_{n, t} \omega\left(N_{t}\right)}{A_{t}}\right]\right\}=0
$$

where $\omega\left(N_{t}\right) \equiv \frac{F\left(N_{t}\right)}{F_{n, t}}$ and $\mu \equiv \frac{\varepsilon}{\varepsilon-1}$ is the steady-state level of markup. Notice that in obtaining (30) we have made used of the fact that $P_{H, t}$ is predetermined from the viewpoint of time t.

In the particular case of fully flexible prices, equation (30) simplifies to:

$$
-\frac{U_{n, t}}{A_{t} F_{n, t} U_{c, t}} g\left(S_{t}\right)=\mu^{-1}
$$

In other words, with flexible prices, each firm would optimally choose to replicate a constant markup. Importantly, the open economy dimension explicitly affects the markup via the presence of the relative price $g\left(S_{t}\right)$, which is positively related to the terms of trade.

At this stage we can propose the following definition of the competitive equilibrium in the small economy:

Definition 1. For any given policy $\left\{R_{t}\right\}$ and processes $\left\{C_{t}^{*}, A_{t}\right\}$, a competitive equilibrium in the small economy with predetermined prices and home bias is a triple $\left\{C_{t}, N_{t}, S_{t}\right\}$ solving (20), (28) and (30).

This definition of the equilibrium allows to determine the remaining set of relevant variables residually. To start with, given $R_{t}$ and $C_{t}$ and an initial condition on $P_{-1}$, the Euler condition (12) allows to determine $P_{t}$. Given $S_{t}$ and therefore $g\left(S_{t}\right)$, we can pin down the domestic producer price level from $P_{H, t}=\frac{P_{t}}{g\left(S_{t}\right)}$. Given $S_{t}, P_{H, t}$ and the foreign price level $P_{t}^{*}$, we can finally derive the equilibrium nominal exchange rate as $\mathcal{E}_{t}=\frac{S_{t} P_{H, t}}{P_{t}^{*}}$. 


\section{Optimal Monetary Policy}

Optimal policy is determined by a monetary authority that, under commitment, maximizes the discounted sum of utility of the representative agent under the constraints that characterize the competitive economy. As in the classical literature on optimal taxation (see Chari, Christiano and Kehoe (1994)) or more recently in the monetary policy closed-economy analysis of Adao et al. (2003) and Khan et al. (2003), the policy problem takes the form of a constrained allocation problem, in which the government can be thought of choosing directly a feasible allocation subject to those constraints that ensure the existence of instruments and prices which make the same allocation consistent with optimality.

In our cashless economy, the minimal set of constraints that are relevant for the Ramsey allocation problem are the ones described in Definition 1. Hence the optimal policy problem for the small economy's planner can be described as follows. Let's define by $\beta^{t} \varphi\left(h^{t}\right), \beta^{t} \lambda\left(h^{t-1}\right)$ and $\beta^{t} \chi\left(h^{t}\right)$ the lagrange multipliers respectively on the feasibility constraint (28), the price implementability constraint (30) and the risk sharing condition (20). Notice that the multiplier on constraint (30) depends on the history of events up to period $t-1$ and is therefore time-invariant as of time $t$.

A constrained optimal allocation is defined by the following problem:

$$
\begin{aligned}
& \operatorname{Max}_{\left\{C_{t}, S_{t}, N_{t}\right\}} E_{0} \sum_{t=0}^{\infty} \beta^{t} U\left(C_{t}, N_{t}\right) \\
& +E_{-1} \sum_{t=0}^{\infty} \beta^{t} \lambda\left(h^{t-1}\right)\left\{\frac{U_{c, t}}{g\left(S_{t}\right)} A_{t} F\left(N_{t}\right)+\mu U_{n, t} \omega\left(N_{t}\right)\right\} \\
& +E_{0} \sum_{t=0}^{\infty} \beta^{t} \varphi\left(h^{t}\right)\left(A_{t} N_{t}-(1-\alpha) g\left(S_{t}\right)^{\eta} C_{t}-\alpha S_{t}^{\eta} C_{t}^{*}\right) \\
& +E_{0} \sum_{t=0}^{\infty} \beta^{t} \chi\left(h^{t}\right)\left(U_{c, t} q\left(S_{t}\right)-U_{c, t}^{*}\right)
\end{aligned}
$$

A peculiar feature of the optimal policy problem when preferences exhibit home bias is that the risk-sharing condition is an explicit constraint of the planner's problem. In the absence of home bias, that constraint would collapse to the equalities $C_{t}=C_{t}^{*}$ and $S_{t}=g\left(S_{t}\right)$, and the policy problem could be rewritten in terms of a less-constrained structure (see more below on this point).

First order conditions for $C_{t}, S_{t}$ and $N_{t}$ read respectively: 


$$
\begin{gathered}
0=U_{c, t}+\lambda\left(h^{t-1}\right) \frac{U_{c c, t}}{g\left(S_{t}\right)} A_{t} F\left(N_{t}\right)-\varphi\left(h^{t}\right)(1-\alpha) g\left(S_{t}\right)^{\eta}+\chi\left(h^{t}\right) U_{c c, t} q\left(S_{t}\right) \\
0=\lambda\left(h^{t-1}\right) U_{c, t} A_{t} F\left(N_{t}\right)\left(-g\left(S_{t}\right)^{-2} g^{\prime}\left(S_{t}\right)\right)+\chi\left(h^{t}\right) U_{c, t} q^{\prime}\left(S_{t}\right) \\
-\varphi\left(h^{t}\right)\left[(1-\alpha) \eta g\left(S_{t}\right)^{\eta-1} g^{\prime}\left(S_{t}\right) C_{t}+\alpha \eta S_{t}^{\eta-1} C_{t}^{*}\right] \\
0=U_{n, t}+\lambda\left(h^{t-1}\right)\left[\frac{U_{c, t} A_{t} F_{n, t}}{g\left(S_{t}\right)}+\mu\left(U_{n n, t} \omega\left(N_{t}\right)+U_{n, t} \omega_{n, t}\right)\right]+\varphi\left(h^{t}\right) A_{t} F_{n, t}
\end{gathered}
$$

Our goal is to establish under what conditions replicating the flexible price allocation coincides with the constrained optimum. In particular, and recalling equation (31), this corresponds to determining whether the planner problem can sustain the term $\Phi_{t} \equiv-\frac{U_{n, t}}{A_{t} F_{n, t} U_{c, t}} g\left(S_{t}\right)$ as a constant.

We proceed as follows. Multiplying and dividing (35) by $\frac{g\left(S_{t}\right)}{U_{c, t} A_{t} F_{n, t}}$ and changing sign we can write:

$$
\Phi_{t}=\lambda\left(h^{t-1}\right)\left(1-\mu \Phi_{t}\left(\zeta_{n, t} \frac{\omega\left(N_{t}\right)}{N_{t}}+\omega_{n, t}\right)\right)+\frac{g\left(S_{t}\right)}{U_{c, t}} \varphi\left(h^{t}\right)
$$

where $\zeta_{n, t} \equiv \frac{U_{n n, t} N_{t}}{U_{n, t}}$.

We can obtain an expression for $\varphi\left(h^{t}\right)$ from $(33)$ :

$$
\varphi\left(h^{t}\right)=\frac{U_{c, t}}{(1-\alpha) g\left(S_{t}\right)^{\eta}}+\lambda\left(h^{t-1}\right) \frac{U_{c c, t} A_{t} F\left(N_{t}\right)}{g\left(S_{t}\right)^{\eta+1}}+\chi\left(h^{t}\right) \frac{U_{c c, t} q\left(S_{t}\right)}{(1-\alpha) g\left(S_{t}\right)^{\eta}}
$$

Notice that the last term in (37) is zero if and only if $\chi\left(h^{t}\right)=0$. This corresponds to the particular case in which the risk-sharing constraint (20) is not explicitly binding in the planner's problem.

Substituting (37) into (36) and rearranging we obtain the following expression:

$$
\Phi_{t}=\frac{\lambda\left(h^{t-1}\right)\left(1-\sigma_{t} K_{\alpha, t}\right)+\frac{g\left(S_{t}\right)^{1-\eta}}{(1-\alpha)}\left(1+\chi\left(h^{t}\right) \frac{U_{c c, t}}{U_{c, t}} q\left(S_{t}\right)\right)}{1+\lambda\left(h^{t-1}\right) \mu\left(\zeta_{n, t} \frac{\omega\left(N_{t}\right)}{N_{t}}+\omega_{n, t}\right)}
$$

where

$$
\begin{aligned}
K_{\alpha, t} & \equiv 1+\frac{\alpha}{1-\alpha} \frac{C_{t}^{*}}{C_{t}} \frac{S_{t}^{\eta}}{g\left(S_{t}\right)^{\eta}} \\
& =(1-\alpha)+\alpha \frac{C_{t}^{*}}{C_{t}} q\left(S_{t}\right)^{\eta}
\end{aligned}
$$


and $\sigma_{t} \equiv-\frac{U_{c c, t} C_{t}}{U_{c, t}}$. Notice that $K_{\alpha, t}=1$ in two cases: (i) closed economy $(\alpha=0)$, or (ii) $P P P$ holding, which implies $C_{t}^{*}=C_{t}$ and $Q_{t}=1$ for all t.

In general, the conditions for a constant markup allocation to coincide with the constrained optimum are the same as the ones that guarantee that the right hand side of (38) is time invariant. For the sake of comparability, and in order to isolate the impact of openness and home bias on the nature of the optimal policy problem, it is convenient to restrict our attention to standard constant elasticity preferences. Hence, in the following, we assume $\zeta_{n, t}=\zeta_{n}$ and $\sigma_{t} \equiv \sigma$, where $\zeta_{n}$ and $\sigma$ are both constant. Let us also assume that the function $F(\bullet)$ specifies to:

$$
F\left(N_{t}\right)=N_{t}^{\xi} \quad \xi \leq 1
$$

Hence, $\omega\left(N_{t}\right)=\frac{N_{t}}{\xi}$ and $\omega_{n, t}=\frac{1}{\xi}$. This is the case for which Adao et al. (2003) - in the context of a closed economy with predetermined prices - show that the constant markup allocation is consistent with the constrained optimum. ${ }^{9}$

Under the above assumptions, and using (28), we can rewrite (38) as follows:

$$
\Phi_{t}=\frac{\lambda\left(h^{t-1}\right)\left(1-\sigma K_{\alpha, t}\right)+\frac{g\left(S_{t}\right)^{1-\eta}}{(1-\alpha)}\left(1+\chi\left(h^{t}\right) \frac{U_{c c, t}}{U_{c, t}} q\left(S_{t}\right)\right)}{1+\lambda\left(h^{t-1}\right) \frac{\mu}{\xi}\left(1+\zeta_{n}\right)}
$$

Thus, in particular, it is easy to see that in a closed economy the above expression reduces to

$$
\Phi_{t}=\frac{\lambda\left(h^{t-1}\right)(1-\sigma)+1}{1+\lambda\left(h^{t-1}\right) \frac{\mu}{\xi}\left(1+\zeta_{n}\right)}
$$

which follows from $g\left(S_{t}\right)=1$ and $\chi\left(h^{t}\right)=0$ for all t. The latter feature, in particular, follows from the fact that in an economy closed to trade (both in assets and goods) the cross-country risk-sharing condition cannot be a constraint in the policy problem.

In an open economy $(\alpha>0)$, and under the maintained assumption of isoelastic preferences, equation (40) identifies two independent sources of optimal deviations from the constant markup allocation. First, movements in the terms of trade $S_{t}$. Second, movements in the real exchange rate $Q_{t}$ (and therefore in $K_{\alpha, t}$ ). Importantly, while variability in the real exchange rate implies variability in the terms of trade, the reverse does not hold in general.

\footnotetext{
${ }^{9}$ Adao et al.(2003) emphasize, however, the non-generality of the constant markup result in the presence of variable expenditure components (such as government purchases) and/or some form of non-isoelastic preferences. To bias our results more in favor of price stability, we have abstracted from the presence of government expenditure shocks.
} 
To better understand the contribution of these two factors to the deviation from a constant markup policy, it is instructive to study the particular case of PPP (absence of home bias), which implies that the movements in the real exchange rate cannot be a source of markup variability in the efficient allocation.

\subsection{PPP: a Particular Case}

Recall that, under PPP, the market clearing condition reduces to (29). In addition, the constraint (20) is not present in the planner's problem. Hence the optimal policy problem reduces to

$$
\operatorname{Max}_{\left\{C_{t}, N_{t}, S_{t}\right\}} E_{0}\left\{\sum_{t=0}^{\infty} \beta^{t} U\left(C_{t}, N_{t}\right)\right\}
$$

subject to (29) and (30). The set of first order conditions reduces to:

$$
\begin{gathered}
U_{c, t}+\lambda\left(h^{t-1}\right) \frac{U_{c c, t}}{g\left(S_{t}\right)} A_{t} F\left(N_{t}\right)=\varphi\left(h^{t}\right) g\left(S_{t}\right)^{\eta} \\
\lambda\left(h^{t-1}\right) U_{c, t} A_{t} F\left(N_{t}\right)\left(-g\left(S_{t}\right)^{-2} g^{\prime}\left(S_{t}\right)\right)=\varphi\left(h^{t}\right) \eta g\left(S_{t}\right)^{\eta-1} g^{\prime}\left(S_{t}\right) C_{t} \\
U_{n, t}+\lambda\left(h^{t-1}\right)\left[\frac{U_{c, t} A_{t} F_{n, t}}{g\left(S_{t}\right)}+\mu\left(U_{n n, t} \omega\left(N_{t}\right)+U_{n, t} \omega_{n, t}\right)\right]=-\varphi\left(h^{t}\right) A_{t} F\left(N_{t}\right)
\end{gathered}
$$

Rearranging these conditions in a similar fashion to above, and once again assuming isoelastic preferences, the expression for $\Phi_{t}$ reduces to:

$$
\Phi_{t}=\frac{\lambda\left(h^{t-1}\right)(1-\sigma)+g\left(S_{t}\right)^{1-\eta}}{1+\lambda\left(h^{t-1}\right) \frac{\mu}{\xi}\left(1+\zeta_{n}\right)}
$$

Hence we see that, in the case of isoelastic preferences, a constant $\Phi_{t}$ can be consistent with the constrained optimum only if $g\left(S_{t}\right)^{1-\eta}$ is a term independent of shocks. This can be achieved either in the case of cross-country perfectly correlated shocks (which do not require relative price adjustments across countries, so that $S_{t}=1$ for all t) or in the case of unitary elasticity of substitution $\eta=1$, which implies Cobb-Douglas consumption preferences. In a more general case, in which $\eta \neq 1$, the constant markup allocation is never consistent with optimality. Under the optimal allocation, a productivity shock requiring a terms of trade depreciation will induce a fall (rise) in $\Phi_{t}$, and therefore a fall (rise) in the price level, whenever $\eta<(>) 1$. The PPP case illustrated above is akin to the two-country case analyzed by Benigno and Benigno (2003). 


\subsection{Forward-Looking Pricing}

So far we have assumed that prices are preset one period. However, the most recent literature on the analysis of optimal policy typically embeds forward-looking forms of price setting in the standard New Keynesian framework.

We assume that changing output prices is subject to some costs. We follow Rotemberg (1982) and model the cost of adjusting prices for each firm $i$ equal to:

$$
\psi_{t}(i) \equiv \frac{\vartheta}{2}\left(\frac{P_{H, t}(i)}{P_{H, t-1}(i)}-1\right)^{2}
$$

where the parameter $\vartheta$ measures the degree of price stickiness. The higher $\vartheta$ the more sluggish is the adjustment of nominal prices. If $\vartheta=0$, prices are flexible.

The cost of price adjustment renders the domestic producer's pricing problem dynamic. Each producer chooses the price $P_{H, t}(i)$ of variety $i$ to maximize expected nominal discounted profits:

$$
E_{t}\left\{\sum_{t=0}^{\infty} \nu_{0, t}\left[P_{H, t}(i) Y_{t}(i)-W_{t} N_{t}(i)-\frac{\vartheta}{2}\left(\frac{P_{H, t}(i)}{P_{H, t-1}(i)}-1\right)^{2} P_{H, t}\right]\right\}
$$

subject to $(21)$ and $(23)$.

In (47), $\nu_{0, t}$ is the time-zero price of one unit of domestic currency to be delivered in time $t$. The first order condition of the above problem reads:

$$
\begin{aligned}
& \nu_{0, t}\left\{(1-\varepsilon)\left(\frac{P_{H, t}(i)}{P_{H, t}}\right)^{-\varepsilon} Y_{t}+\varepsilon \frac{W_{t}}{P_{H, t}} h^{\prime}(\bullet)\left(\frac{P_{H, t}(i)}{P_{H, t}}\right)^{-\varepsilon-1} \frac{Y_{t}}{A_{t}}\right\} \\
= & \nu_{0, t} P_{H, t} \vartheta\left(\frac{P_{H, t}(i)}{P_{H, t-1}(i)}-1\right) \frac{1}{P_{H, t-1}(i)}-E_{t}\left\{\nu_{0, t+1} P_{H, t+1} \vartheta\left(\frac{P_{H, t+1}(i)}{P_{H, t}(i)}-1\right) \frac{P_{H, t+1}(i)}{P_{H, t}(i)^{2}}\right\}
\end{aligned}
$$

Dividing through by $\nu_{0, t}$ and imposing a symmetric equilibrium (which implies $P_{H, t}(i)=P_{H, t}$ for all $\mathrm{i}$ and $\mathrm{t}$ ) we can rewrite:

$$
\begin{aligned}
\pi_{H, t}\left(\pi_{H, t}-1\right)= & \beta E_{t}\left\{\frac{U_{c, t+1}}{U_{c, t}} \frac{g\left(S_{t}\right)}{g\left(S_{t+1}\right)} \pi_{H, t+1}\left(\pi_{H, t+1}-1\right)\right\} \\
& +\frac{\varepsilon Y_{t}}{\vartheta}\left(\frac{\frac{W_{t}}{P_{t}}}{A_{t} F_{n, t}} g\left(S_{t}\right)-\frac{\varepsilon-1}{\varepsilon}\right)
\end{aligned}
$$


where $\pi_{H, t} \equiv \frac{P_{H, t}}{P_{H, t-1}}$ and where we have used the fact that, from $(10), \frac{\nu_{0, t+1}}{\nu_{0, t}}=\frac{\beta \frac{U_{c, t+1}}{P_{t+1}}}{\frac{U_{c, t}}{P_{t}}}$. The above equation has the form of a non-linear forward-looking New-Keynesian Phillips curve. ${ }^{10}$ Notice that the openness dimension affects the form of the Phillips curve via movements in the terms of trade. The latter affect both the form of the stochastic discount factor $\frac{U_{c, t+1}}{U_{c, t}} \frac{g\left(S_{t}\right)}{g\left(S_{t+1}\right)}$ as well as the marginal cost expression $\frac{W_{t}}{A_{t} F_{n, t} P_{t}} g\left(S_{t}\right)$.

Substituting (9) and the symmetric equilibrium version of (21), which implies $A_{t} F\left(N_{t}(i)\right)=$ $A_{t} F\left(N_{t}\right)$ for all $i$, we can write (49) in terms of real allocations only :

$$
\begin{aligned}
\pi_{H, t}\left(\pi_{H, t}-1\right)= & \beta E_{t}\left\{\frac{U_{c, t+1}}{U_{c, t}} \frac{g\left(S_{t}\right)}{g\left(S_{t+1}\right)} \pi_{H, t+1}\left(\pi_{H, t+1}-1\right)\right\} \\
& +\frac{\varepsilon A_{t} F\left(N_{t}\right)}{\vartheta}\left(-\frac{U_{n, t}}{U_{c, t} A_{t} F_{n, t}} g\left(S_{t}\right)-\frac{\varepsilon-1}{\varepsilon}\right)
\end{aligned}
$$

Equation (50) is a modified Phillips curve equation suitable for the policy allocation problem to be analyzed below. Notice that, as a consequence of forward-looking price setting, it is unfeasible to eliminate inflation in the minimal set of conditions that summarize the competitive equilibrium and which must be part of the planner's allocation problem.

To complete the set of restrictions that will be relevant for the optimal policy problem, notice that the resource constraint will now comprise a price adjustment cost factor, and therefore will read:

$$
Y_{t}=(1-\alpha) g\left(S_{t}\right)^{\eta} C_{t}+\alpha S_{t}^{\eta} C_{t}^{*}+\frac{\vartheta}{2}\left(\pi_{H, t}-1\right)^{2}
$$

\subsection{Optimal Monetary Policy with Forward-Looking Pricing}

The presence of the forward-looking pricing condition (50) alters the form of the policy problem in a fundamental way. Once again, we assume that planner in the small economy can resort to commitment. Let's define by $\left\{\lambda_{p, t}, \lambda_{f, t}, \lambda_{r, t}\right\}_{t=0}^{\infty}$ a sequence of lagrange multipliers on constraints (50), (51) and (20) respectively. The planner's problem can now be characterized as follows:

$$
\operatorname{Max}_{\left\{C_{t}, N_{t}, S_{t}, \pi_{H, t}\right\}} E_{0} \sum_{t=0}^{\infty} \beta^{t} U\left(C_{t}, N_{t}\right)
$$

\footnotetext{
${ }^{10}$ For a log-linear Phillips curve derived in the context of the so called Calvo-Yun model, see Woodford (2003a) and Gali and Gertler (1999).
} 


$$
\begin{aligned}
& +E_{0} \sum_{t=0}^{\infty} \beta^{t} \lambda_{p, t}\left[\begin{array}{c}
\pi_{H, t}\left(\pi_{H, t}-1\right)-\beta E_{t}\left\{\frac{U_{c, t+1}}{U_{c, t}} \frac{g\left(S_{t}\right)}{g\left(S_{t+1}\right)} \pi_{H, t+1}\left(\pi_{H, t+1}-1\right)\right\} \\
-\frac{\varepsilon A_{t} F\left(N_{t}\right)}{\vartheta}\left(-\frac{U_{n, t}}{U_{c, t} A_{t} F_{n, t}} g\left(S_{t}\right)-\frac{\varepsilon-1}{\varepsilon}\right)
\end{array}\right] \\
& +E_{0} \sum_{t=0}^{\infty} \beta^{t} \lambda_{f, t}\left[A_{t} F\left(N_{t}\right)-(1-\alpha) g\left(S_{t}\right)^{\eta} C_{t}-\alpha S_{t}^{\eta} C_{t}^{*}-\frac{\vartheta}{2}\left(\pi_{H, t}-1\right)^{2}\right] \\
& +E_{0} \sum_{t=0}^{\infty} \beta^{t} \lambda_{r, t}\left(U_{c, t} q\left(S_{t}\right)-U_{c, t}^{*}\right)
\end{aligned}
$$

As a result of the constraint (50) exhibiting future expectations of control variables, the maximization problem as spelled out in (52) is intrinsically non-recursive. ${ }^{11}$ As first emphasized in Kydland and Prescott (1980), and then developed in Marcet and Marimon (1999), a formal way to rewrite the same problem in a recursive stationary form is to enlarge the planner's state space with additional (pseudo) costate variables. In our particular case, the enlarged state space is simply composed by the vector $\left(A_{t}, Z_{t}\right)$ where $Z_{t} \equiv \lambda_{p, t-1}$. The lagged multiplier $\lambda_{p, t-1}$ bears the crucial meaning of tracking, along the dynamics, the value to the planner of committing to the pre-announced policy plan. ${ }^{12}$

For any given process $\left\{C_{t}^{*}\right\}$, first order efficiency conditions with respect to $\pi_{H, t}, C_{t}, S_{t}, N_{t}$ for $t>0$ read:

$$
\begin{gathered}
\frac{U_{c, t}}{g\left(S_{t}\right)}\left(2 \pi_{H, t}-1\right)\left(\lambda_{p, t}-\lambda_{p, t-1}\right)=\lambda_{f, t} \vartheta\left(\pi_{H, t}-1\right) \\
0=U_{c, t}+\frac{\pi_{H, t}\left(\pi_{H, t}-1\right)}{g\left(S_{t}\right)} U_{c c, t}\left(\lambda_{p, t}-\lambda_{p, t-1}\right) \\
+\lambda_{p, t}(\varepsilon-1) \frac{A_{t} F\left(N_{t}\right)}{\vartheta} U_{c c, t}-\lambda_{f, t}(1-\alpha) g\left(S_{t}\right)^{\eta}+\lambda_{r, t} U_{c c, t} q\left(S_{t}\right) \\
\left(-g\left(S_{t}\right)^{-2} g^{\prime}\left(S_{t}\right)\right)\left[U_{c, t}\left(\pi_{H, t}-1\right) \pi_{H, t}\left(\lambda_{p, t}-\lambda_{p, t-1}\right)+\lambda_{p, t}(\varepsilon-1) U_{c, t} \frac{A_{t} F\left(N_{t}\right)}{\vartheta}\right] \\
=\lambda_{f, t}\left((1-\alpha) \eta g\left(S_{t}\right)^{\eta-1} g^{\prime}\left(S_{t}\right) C_{t}-\eta S_{t}^{\eta-1} C_{t}^{*}\right)+\lambda_{r, t} U_{c, t} q^{\prime}\left(S_{t}\right)
\end{gathered}
$$

\footnotetext{
${ }^{11}$ See Kydland and Prescott (1977), Calvo (1978). As such the system does not satisfy per se the principle of optimality, according to which the optimal decision at time $\mathrm{t}$ is a time invariant function only of a small set of state variables.

${ }^{12}$ If one or more constraints featured expectations extending more than one period in the future, the set of costate variables would be enlarged accordingly (see Marcet and Marimon, 1999).
} 


$$
1+\lambda_{p, t}\left\{\frac{\varepsilon g\left(S_{t}\right)}{\vartheta U_{c, t}}\left(\frac{U_{n n, t} N_{t}}{U_{n, t}} \frac{\omega\left(N_{t}\right)}{N_{t}}+\omega_{n, t}\right)+\frac{(\varepsilon-1)}{\vartheta} \frac{A_{t} F_{n, t}}{U_{n, t}}\right\}+\lambda_{f, t} \frac{A_{t} F_{n, t}}{U_{n, t}}=0
$$

where we recall that $\omega\left(N_{t}\right) \equiv \frac{F\left(N_{t}\right)}{F_{n, t}}$.

The system (53)-(56) is recursive in the state space $\left(A_{t}, Z_{t}\right)$ for $t>0$. As in Khan et al. (2003), to avoid a typical non-recursivity problem at time $t=0$, we assume that the initial value of the multiplier $\lambda_{p,-1}$ is set at the steady-state value implicit in the system (53)-(56). We refer to the steady-state version of equations (53)-(56) as the deterministic Ramsey steady state. We proceed to analyze its properties below.

\subsubsection{Ramsey Steady State}

To determine the long-run inflation rate associated to the optimal policy problem above, one needs to solve the steady-state version of the set of efficiency conditions (53)-(56). ${ }^{13}$ In that steady-state, we have $\lambda_{p, t}=\lambda_{p, t-1}$. Hence condition (53) immediately implies:

$$
\lambda_{f} \vartheta\left(\pi_{H}-1\right)=0
$$

Since $\lambda_{f}>0$ (the resource constraint must hold with equality) and $\vartheta>0$ (we are not imposing $a$ priori that the steady-state coincides with the flexible price allocation), in turn (57) must imply $\pi_{H}=1$. Hence the Ramsey planner would like to generate an average (net) inflation rate of zero. The intuition for why the the long-run optimal inflation rate is zero is simple. Under commitment, the planner cannot resort to ex-post inflation as a device for eliminating the inefficiency related to market power in the goods market. Hence the planner aims at choosing that rate of inflation that allows to minimize the cost of adjusting prices, and summarized by the quadratic term $\frac{\vartheta}{2}\left(\pi_{H, t}-1\right)^{2}$.

One may wonder why the openness dimension does not apparently exert any influence on the desired optimal long-run inflation rate. In light of our analysis above, the desire of adjusting the terms of trade and/or the real exchange rate (under home bias) has been shown to be a sufficient motive for inducing the planner to deviate from choosing a constant markup allocation. However, these considerations can drive the planner's behavior only in the presence of equilibrium fluctuations

\footnotetext{
${ }^{13}$ To develop an analogy with the Ramsey-Cass-Koopmans model, this amounts to computing the modified golden rule steady state. This per se contrasts with the golden rule inflation rate, which would correspond to the one that maximizes households' instantaneous utility under the requirement that the planner is constrained to choose only among constant allocations. In dynamic economies with discounted utility the two concepts of long-run optimal policy do not coincide. See King and Wolman (1999) and Khan et al. (2003) for a closed-economy analysis on this point. See Faia and Monacelli (2004) for additional discussion in the context of a two-country model.
} 
around the same long-run steady state and induced by country-specific shocks. It is only in the presence of such shocks that variations in (international) relative prices are efficiently calibrated to implement the optimal allocation. In other words, under commitment, the planner cannot on average resort to movements in inflation to alter the relative purchasing power of domestic residents. Thus, under commitment, the desire to influence the terms of trade and/or the real exchange rate shapes the optimal policy behavior only outside the long-run steady state.

\subsection{Dynamics under the Optimal Policy and the Effect of Home Bias}

In this section we study the equilibrium dynamics under the optimal policy in response to productivity shocks. In particular, our goal is to assess the extent to which home bias affects the optimal volatility of inflation. In conducting our analysis we specialize utility to be $U\left(C_{t}, N_{t}\right)=$ $\frac{1}{1-\sigma} C_{t}^{1-\sigma}-\frac{1}{1+\zeta} N_{t}^{1+\zeta}$ and the production technology to be $Y_{t}=A_{t} N_{t}$. The time unit is meant to be quarters. The discount factor $\beta$ is equal to 0.99. The degree of risk aversion $\sigma$ is 1 (which implies log-utility), the inverse elasticity of labor supply $\zeta$ is equal to 3 , which is a common value in the real business cycle literature. As a benchmark, we set the elasticity of substitution between domestic and foreign goods $\eta$ equal to 1.5. The literature is largely polarized on the likely value of this parameter. Obstfeld and Rogoff (2000) summarize the related micro empirical trade literature, which suggests values in the range $[8,10]$ (see also Anderson and Van Wincoop (2004)). The current New Open Macroeconomics literature usually adopts much lower values, in the range [1,2]. Many normative results in this literature hinge on the assumed value of this parameter. ${ }^{14}$

In order to parameterize the degree of price stickiness, we observe that, by log-linearizing equation (50) around a zero-inflation steady-state, we can obtain an elasticity of inflation to real marginal cost (normalized by the steady-state level of output) ${ }^{15}$ that takes the form $\frac{\varepsilon-1}{\vartheta}$. This allows a direct comparison with empirical studies on the New Keynesian Phillips curve such as Galí and Gertler (1999) and Sbordone (2002) using a Calvo approach. In those studies, the slope coefficient of the log-linear Phillips curve can be expressed as $\frac{(1-\delta)(1-\beta \delta)}{\delta}$, where $\delta$ is the probability of not resetting the price in any given period. For any given values of $\varepsilon$, which entails a choice on the steady-state level of the markup, we can thus build a mapping between the frequency of price adjustment in the Calvo model $\frac{1}{1-\delta}$ and the degree of price stickiness $\vartheta$ in the Rotemberg

\footnotetext{
${ }^{14}$ See Pappa (2004), Sutherland (2004), Benigno and Benigno (2003).

${ }^{15}$ To produce a slope coefficient directly comparable to the empirical literature on the New Keynesian Phillips curve this elasticity needs to be normalized by the level of output when the price adjustment cost factor is not explicitly proportional to output, as assumed here.
} 
setup. Traditionally, the sticky price literature has been considering a frequency of four quarters as a realistic value. Recently, Bils and Klenow (2004) argue that the observed frequency of price adjustment is much higher in the US, and in the order of two quarters. In their comprehensive study on Europe (which includes small open economies such as Belgium and Spain), Angeloni et al. (2005) find evidence of lower frequency of price adjustment, and in the order of four quarters. Hence we parameterize $\frac{1}{1-\delta}=4$, which implies $\delta=0.75$. Setting the elasticity $\varepsilon$ equal to 7.5 , which implies a steady-state markup of 15 percent, the resulting stickiness parameter satisfies $\vartheta=\frac{\delta(\varepsilon-1)}{(1-\delta)(1-\beta \delta)}=75$.

As a benchmark, we set the share of foreign imported goods in the domestic consumption basket (degree of openness) to a value of 0.4. However, we will conduct a series of sensitivity experiments on the value of this parameter. Finally (log) productivity is assumed to follow an autoregressive process:

$$
\log \left(A_{t}\right)=\rho^{a} \log \left(A_{t-1}\right)+\varepsilon_{t}^{a}
$$

where $\rho^{a}=0.9$ and $\varepsilon_{t}^{a}$ is an i.i.d. shocks with standard deviation $\sigma^{\varepsilon}=0.01$.

Our solution strategy consists in generating a log-linear approximation of the Ramsey equilibrium conditions (53)-(56) around the deterministic Ramsey steady state. ${ }^{16}$

\subsubsection{Responses to Productivity Shocks and the Effect of Varying Openness}

Figure 1 displays impulse responses of the domestic price level, nominal exchange rate, consumption and real exchange rate to a one percent rise in Home productivity under the Ramsey policy. All responses are compared for alternative values of the degree of openness $\alpha$. Recall that, in our framework, the limit case of absence of home bias corresponds to $\alpha \rightarrow 1$. This is a limit case in the sense that, for $\alpha$ approaching 1, the consumption basket of the small economy tends to coincide with the one of the rest of world (which per se corresponds to a closed economy).

Our simulations are conducted under two assumptions. First, the intratemporal elasticity of substitution $\eta$ is assumed equal 1. This assumption entails that the terms of trade motive for domestic markup variability is (temporarily) shut-down. Second, monetary policy in the rest of the world is assumed to be conducted in terms of strict inflation targeting, so that $\pi_{F, t}^{*}=1$ for all $t$.

\footnotetext{
${ }^{16}$ By applying perturbation methods employed in the Matlab routines of Schmitt-Grohe and Uribe (and available at the website http://www.econ.duke.edu/ grohe), I also solved the Ramsey equilibrium conditions up to an approximation of order two. This is to eventually account for the observation in Chari et al. (1995) that log-linear approximations of Ramsey systems may be inaccurate. Results were virtually unaltered.
} 
Thus the figure is representative of the role that home bias (inverse degree of openness) plays in the optimal setting of policy. In response to higher productivity, the equilibrium adjustment requires an increase in the demand of domestic goods relative to foreign goods. This is achieved by means of a terms of trade and real exchange rate depreciation (as well as via a depreciation of the nominal exchange rate). Intuitively, the size of the response of the real exchange rate is decreasing in $\alpha$, for the limit case of $\alpha=1$ corresponds to the one in which PPP holds. The required nominal depreciation is also decreasing in $\alpha$, but this effect does not tend to vanish when the environment approaches the PPP case. In the PPP case, in fact, the equilibrium adjustment still requires a depreciation of the terms of trade.

Importantly, and even in the case $\eta=1$, we observe that strict (producer) price stabilization is not part of the optimal policy program. Furthermore, the magnitude of the response of the price level is not monotonic in $\alpha$. The largest response of the price level is obtained for intermediate values of openness. The intuition for this result is simple. From the point of view of the optimal markup policy, both limit cases of $\alpha \rightarrow 0$ (no trade openness) and $\alpha \rightarrow 1$ (PPP, or absence of home bias) mimic the situation of a closed economy. In that particular case, a large (and related) closed economy literature has pointed out that the optimal policy prescription coincides with strict price stabilization (Woodford (2003a), Clarida et al. (1999)). ${ }^{17}$

Notice also that the price level is stationary under the Ramsey allocation. This is reminiscent of the history dependence feature of optimal policy emphasized in the same recent closed economy literature. ${ }^{18}$ In turn, stationarity of the price level, coupled with stationarity in the terms of trade (which is a feature of this economy under complete markets), generates the mean reverting behavior of the nominal exchange rate.

Figure 2 displays the effects of varying $\alpha$ on the equilibrium responses to a productivity shock in the case $\eta=2$. Notice that in this case it is not only the real exchange rate response to be affected by alternative values of openness, but also the response of the nominal exchange rate (and of the terms of trade). As openness increases, the optimal policy prescribes enhanced smoothing of the nominal exchange rate. Intuitively, since higher values of $\alpha$ correspond to smaller degrees of

\footnotetext{
${ }^{17}$ However, Adao et al. (2003) refine this proposition in the closed economy case. They show that the strict markup stabilization result popularized, among others, by the work of Rotemberg and Woodford (1997), Woodford (2003a), Clarida et al. (1999), Khan et al. (2003), does not generalize to all types of utility functions and ceases to hold in the presence, for instance, of variable government expenditure.

${ }^{18}$ See Woodford (2003b).
} 
home bias, the real exchange motive for nominal exchange rate adjustment is dampened relative to the necessity of inducing an adjustment in the terms of trade. Once again, a stronger response of the price level is obtained in the intermediate case of openness.

The latter result motivates further simulation analysis whose output is displayed in Figure 3. The figure displays the effects of varying openness on the volatility of inflation, the terms of trade and the real exchange rate under the optimal policy. All values are expressed in percent terms. In this case we assume that the only source of shocks is domestic productivity and maintain a value of $\eta=2$. Hence we see that, in line with our impulse response results, optimal inflation volatility is U-shaped in the degree of trade openness. On the other hand, the volatility of the real exchange rate and of the terms of trade is monotonically decreasing in $\alpha$.

In Figure 4 we extend the set of shocks to include a foreign output shock. Hence we assume that $Y_{t}^{*}=C_{t}^{*}=\rho^{*} Y_{t-1}^{*}+\varepsilon_{t}^{*}$, with $\rho^{*}=0.9$, and $\sigma_{t}^{\varepsilon^{*}}=0.01$. Notice that optimal inflation volatility increases, although, at the peak, it remains quite low. On the other hand, for a sufficiently high degree of home bias, the volatility of the real exchange rate and of terms of trade becomes sizeable and in the order of five percent. Thus we see that, under the optimal policy, high home bias can be a potentially vigorous source of nominal and real exchange rate volatility.

\section{Conclusions}

An important strand of the recent open economy New Keynesian literature has focused on the issue of optimal monetary and exchange rate policy. However, these contributions have remained largely disconnected from the traditional Ramsey-type approach that has been peculiar to the optimal monetary and fiscal policy literature of closed economy flexible-price models.

This paper characterizes optimal monetary policy in a small open economy with nominal rigidities and home bias in trade. Specific to our approach is a Ramsey-type analysis of the optimal policy problem. In this context, home bias in consumption emerges as an independent factor contributing to deviations from the typical closed-economy paradigm of strict markup stabilization. In this respect, and given that home bias is a prominent feature of international trade data, the nature of optimal monetary policy in an open economy emerges as fundamentally different from the one of a closed economy.

Our analysis lends itself to several possible extensions. First, and within the same Ramseytype approach, one may explore the role of alternative sources of real exchange rate volatility, 
such as deviations from the law of one price induced either by stickiness in import prices or by the presence of distributions costs (Burstein et al. (2003), Corsetti and Dedola (2004). Second, one may observe that home bias is a fundamental feature of international trade data not only in consumption but also in equities (Engel and Matsumoto (2005)). The extension of our setup to the analysis of optimal exchange rate policy with a simultaneous presence of home bias in goods and equities is an interesting avenue of research which we are exploring in ongoing complementary work. 


\section{References}

[1] Adao, B., Correia, I., P. Teles, (2003), "Gaps and Triangles", Review of Economic Studies, 60, 4.

[2] Angeloni, I., L. Aucremanne, M. Ehrmann, J. Galí, A. Levin, F. Smets (2005), " New Evidence on Inflation Persistence and Price Stickiness in the Euro Area: Implications for Macro Modelling", September 2005.

[3] Anderson J. and E. Van Wincoop (2004), "Trade Costs", Journal of Economic Literature.

[4] Atkinson, A. B. and J. Stiglitz, (1976), "The Design of Tax Structure: Direct Versus Indirect Taxation", Journal of Public Economics, 6, 1-2, 55-75.

[5] Backus, D., P.K Kehoe and F. E. Kydland (1995), "International Business Cycles: Theory and Evidence", in Frontiers of Business Cycle Research, Edited by Thomas F. Cooley, Princeton University Press.

[6] Benigno, P. and G. Benigno, (2003), "Price Stability Open Economies", Review of Economic Studies, 60,4.

[7] Benigno, P. and G. Benigno, (2004), "Implementing Monetary Cooperation Through Inflation Targeting", forthcoming Journal of Monetary Economics.

[8] Benigno, P. and M. Woodford (2004), "Inflation Stabilization and Welfare: The Case of a Distorted Steady State", Journal of the European Economic Association forthcoming.

[9] Bils M. and P. Klenow (2004), "Some Evidence on the Importance of Sticky Prices", Journal of Political Economy, October.

[10] Burstein A., J. Neves and S. Rebelo (2003), "Distribution Costs and Real Exchange Rate Dynamics," Journal of Monetary Economics, September 2003.

[11] Calvo G. (1978), "On the Time Consistency of Optimal Policy in a Monetary Economy", Econometrica, vol. 46, issue 6, pages 1411-28

[12] Chari, V.V. and P.J. Kehoe, (1999), "Optimal Fiscal and Monetary Policy", in Handbook of Macroeconomics, M. Woodford and J. Taylor Eds, North Holland. 
[13] Chari, V.V., L. J. Christiano and P.J. Kehoe (1991), "Optimal Fiscal and Monetary Policy: Some Recent Results", Journal of Money, Credit and Banking, 23:519 539.

[14] Chari V. V. , L. J. Christiano and P.J. Kehoe, (1994), "Optimal Fiscal Policy in A Business Cycle Model”, Journal of Political Economy, 102:617 652.

[15] Chari V. V. , L. J. Christiano and P.J. Kehoe, (1995), "Policy Analysis in Business Cycle Models", in Frontiers of Business Cycle Research, T. Cooley Ed.

[16] Chari, V.V., P.J. Kehoe, and E. McGrattan (2002): "Can Sticky Price Models Generate Volatile and Persistent Real Exhange Rates?," Review of Economic Studies 69, 533-563.

[17] Clarida, R., J. Galí, and M. Gertler (1999): "The Science of Monetary Policy: A New Keynesian Perspective," Journal of Economic Literature, vol. 37, 1661-1707.

[18] Clarida, R., J. Galí, and M. Gertler (2002): "A Simple Framework for International Monetary Policy Analysis," Journal of Monetary Economics, vol. 49, no. 5, 879-904.

[19] Corsetti, G. and P. Pesenti (2001): "Welfare and Macroeconomic Interdependence," Quarterly Journal of Economics vol. CXVI,issue 2, 421-446.

[20] Corsetti, G. and P. Pesenti (2003): "International Dimensions of Optimal Monetary Policy", Journal of Monetary Economics.

[21] Corsetti, G. and L. Dedola (2004)," Macroeconomics of International Price Discrimination", forthcoming Journal of International Economics.

[22] De Fiore F. and Z. Liu (2005), "Does Trade Openness Matter for Aggregate Instability?", Journal of Economic Dynamics and Control, Vol. 29(7), July 2005, pp. 1165-1192.

[23] De Paoli B. (2004), "Monetary Policy and Welfare in a Small Open Economy", CEP Discussion Paper 369, May.

[24] Devereux, M. and C. Engel (2003), "Monetary Policy in the Open Economy Revisited: Exchange Rate Flexibility and Price Setting Behavior," Review of Economic Studies, 60, 765-783.

[25] Engel C. and A. Matsumoto (2005), "Portfolio Choice in a Monetary Open-Economy DSGE Model", Mimeo, University of Wisconsin. 
[26] Faia E. and T. Monacelli (2004), "Ramsey Monetary Policy and International Relative Prices", ECB w.p 344, April.

[27] Friedman, M. (1959), "The Optimum Quantity of Money", in The Optimum Quantity of Money, and Other Essays, Aldine Publishing Company, Chicago.

[28] Galí, J. and M. Gertler (1999),"Inflation Dynamics: A Structural Econometric Analysis", Journal of Monetary Economics, vol. 44, nº 2, 195-222.

[29] Galí, J. and T. Monacelli (2002), " Monetary Policy and Exchange Rate Volatility in A Small Open Economy", NBER w.p 8905.

[30] Galí, J. and T. Monacelli, (2005), " Monetary Policy and Exchange Rate Volatility in A Small Open Economy", Review of Economic Studies, Volume 72, Number 3.

[31] Goodfriend, M. and R. King (2000), "The Case for Price Stability", European Central Bank Conference on "Price Stability".

[32] Khan, A., R. King and A.L. Wolman, (2003), "Optimal Monetary Policy", Review of Economic Studies, 60,4.

[33] King, R. and A. L. Wolman (1999), "What Should the Monetary Authority Do When Prices Are Sticky", in Taylor, J. B., ed., Monetary Policy Rules, Chicago: university of Chicago Press, 349-398.

[34] Kollmann, R. (2001): "The Exchange Rate in a Dynamic Optimizing Current Account Model with Nominal Rigidities: A Quantitative Investigation," Journal of International Economics vol.55, 243-262.

[35] Kollmann, R. (2003): "Monetary Policy Rules in the Open Economy: Effects on Welfare and Business Cycles", Journal of Monetary Economics 2002, Vol.49, pp.989-1015.

[36] Kydland, F. and E. C. Prescott, (1977), "Rules Rather Than Discretion: The Inconsistency of Optimal Plans", Journal of Political Economy, 1977, vol. 85, issue 3, pages 473-91.

[37] Kydland, F. and E. C. Prescott, (1980), "Dynamic Optimal Taxation, Rational Expectations and Optimal Control", Journal of Economic Dynamics and Control, 2:79-91. 
[38] Lucas, R. E. and N. Stokey, (1983), "Optimal Fiscal and Monetary Policy in an Economy Without Capital", Journal of Monetary Economics, 12:55-93.

[39] Marcet, A. and R. Marimon, (1999), "Recursive Contracts", mimeo, Universitat Pompeu Fabra and European University Institute.

[40] McCallum B. and E. Nelson (2000) "Monetary Policy for an Open Economy: An Alternative Framework with Optimizing Agents and Sticky Prices", Oxford Review of Economic Policy 16, 74-91.

[41] Obstfeld M. and K. Rogoff (2000), "The Sux Major Puzzles in International Macroeconomics: Is There a Common Cause?", Macroeconomics Annual, B. Bernanke and K. Rogoff eds.

[42] Pappa, E., (2004), "Do the ECB and the Fed really need to Cooperate? Optimal Monetary Policy in a Two-Country World", Journal of Monetary Economics.

[43] Ramsey, F. P., (1927), "A contribution to the Theory of Taxation", Economic Journal, 37:4761.

[44] Rotemberg, J. and M. Woodford (1997), "An Optimizing Based Econometric Framework for the Evaluation of Monetary Policy", in B. Bernanke and J. Rotemberg, eds., NBER Macroeconomics Annual, Cambridge, MA, MIT Press.

[45] Sbordone A. (2002), "Prices and Unit Labor Costs: A New Test of Price Stickiness", Journal of Monetary Economics Vol. 49 (2).

[46] Schmitt-Grohe, S. and M. Uribe (2004), "Optimal Fiscal and Monetary Policy under Sticky Prices", Journal of Economic Theory, 114,198-230.

[47] Siu, H. (2004) "Optimal Fiscal and Monetary Policy with Sticky Prices", Journal of Monetary Economics 51(3), April.

[48] Sutherland, A. (2002), "International Monetary Policy Coordination and Financial Market Integration" CEPR Discussion Paper No 4251.

[49] Sutherland A. (2005), ""Incomplete Pass-Through and the Welfare Effects of Exchange Rate Variability" Journal of International Economics, 2005, 65, 375-399. 
[50] Woodford, M. (2003a), "Interest \& Prices", Princeton University Press.

[51] Woodford, M. (2003b), "Optimal Monetary Policy Inertia", Review of Economic Studies, 60,4.

[52] Yun, T., (1996), "Nominal Price Rigidity, Money Supply Endogeneity, and Business Cycle", Journal of Monetary Economics, 37: 345-370. 
Figure 1. Responses to a Productivity Shock under Ramsey Policy (ETA=1)
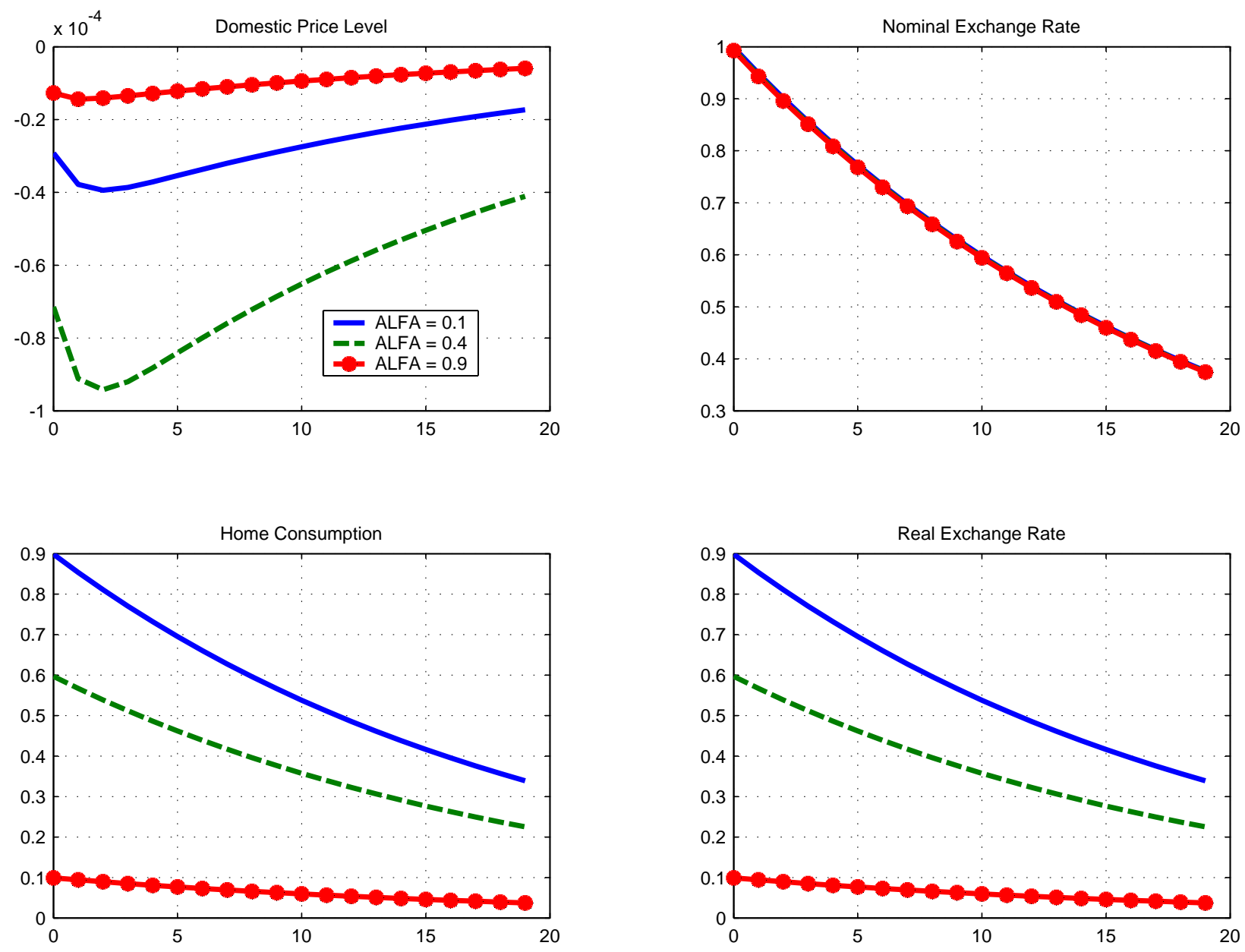
Figure 2. Responses to a Productivity Shock under Ramsey Policy (ETA=2)
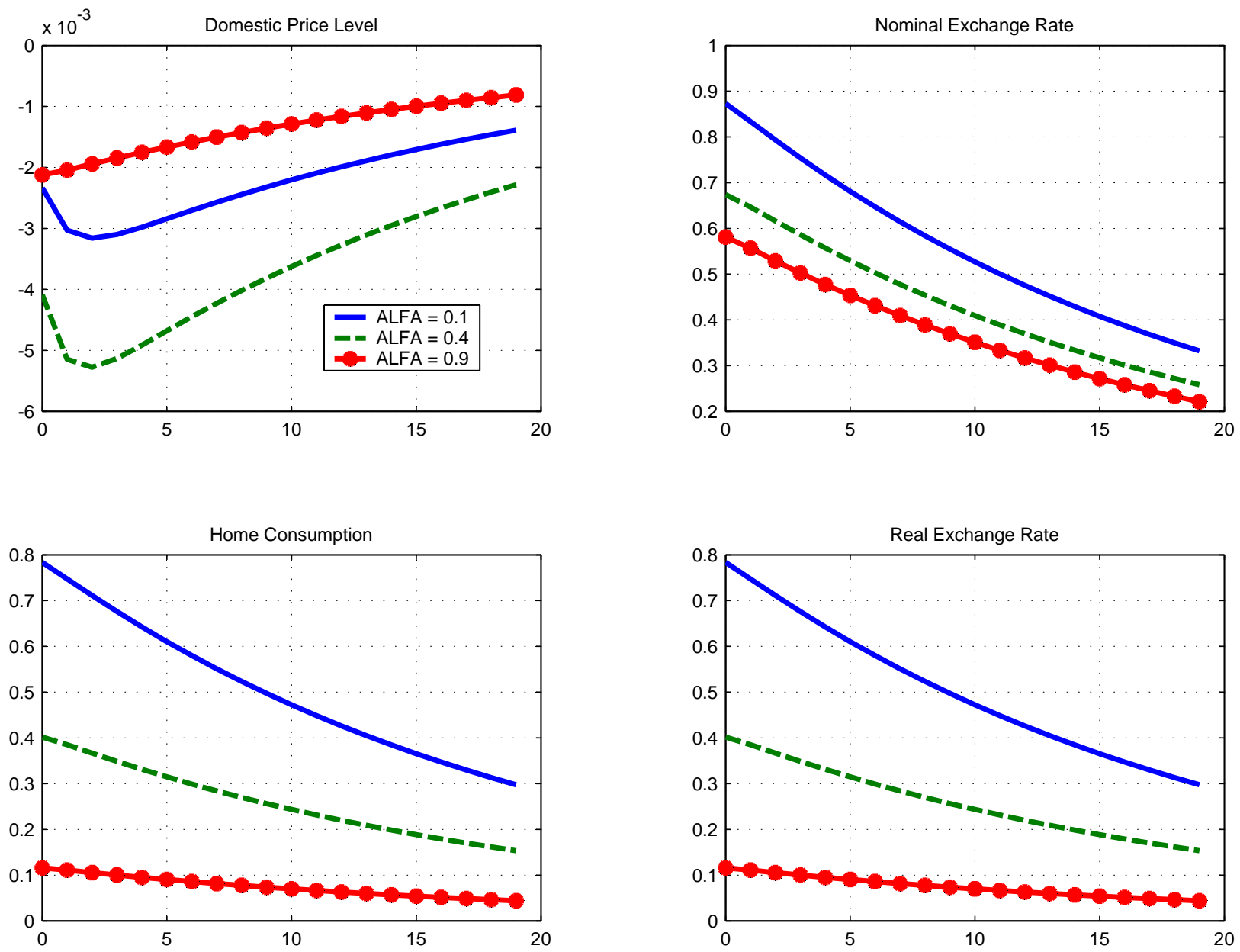
Figure 3. Volatility under Ramsey Policy: Effect of Varying Openness (domestic shocks)
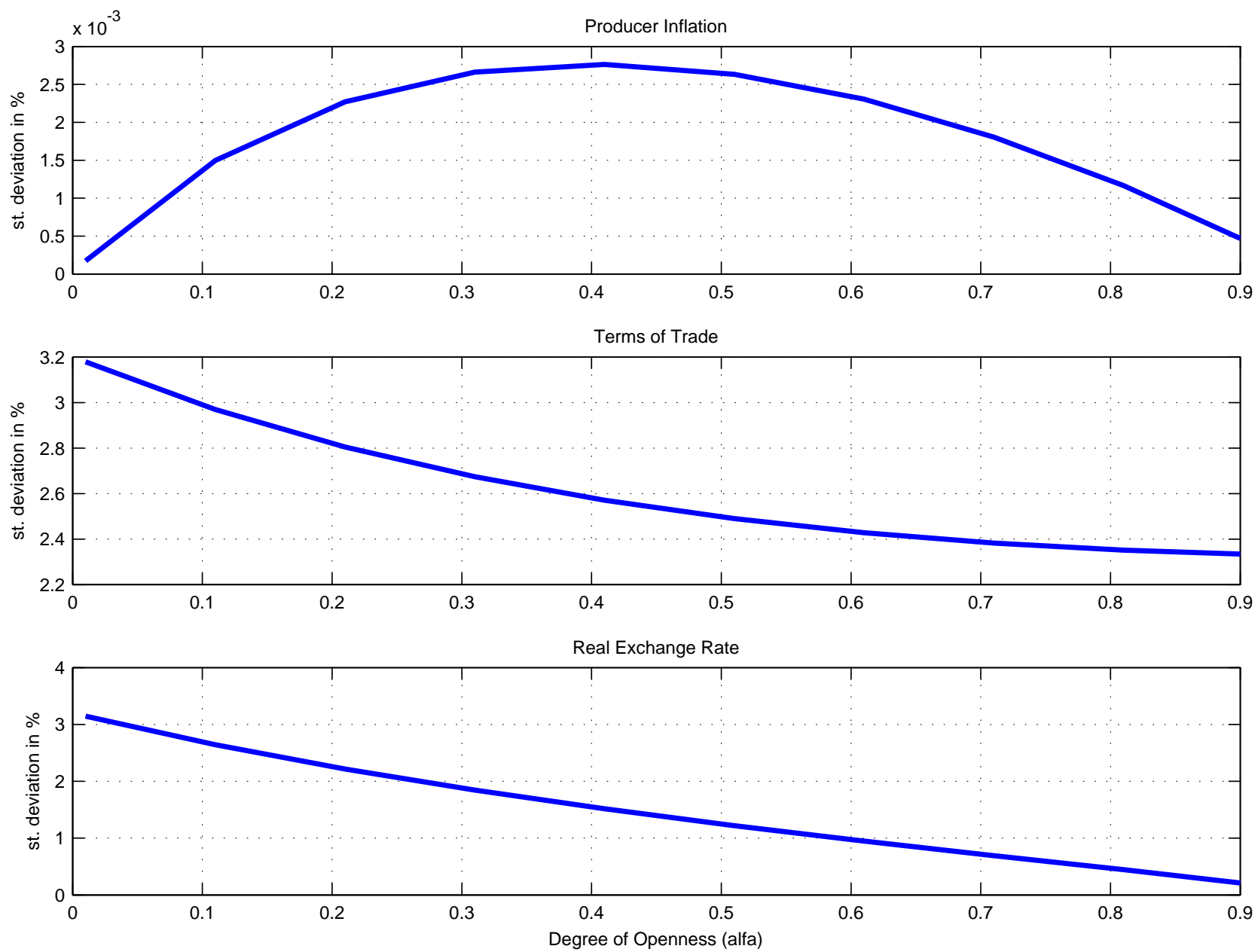
Figure 4. Volatility under Ramsey Policy: Effect of Varying Openness (dom. and for. shocks)
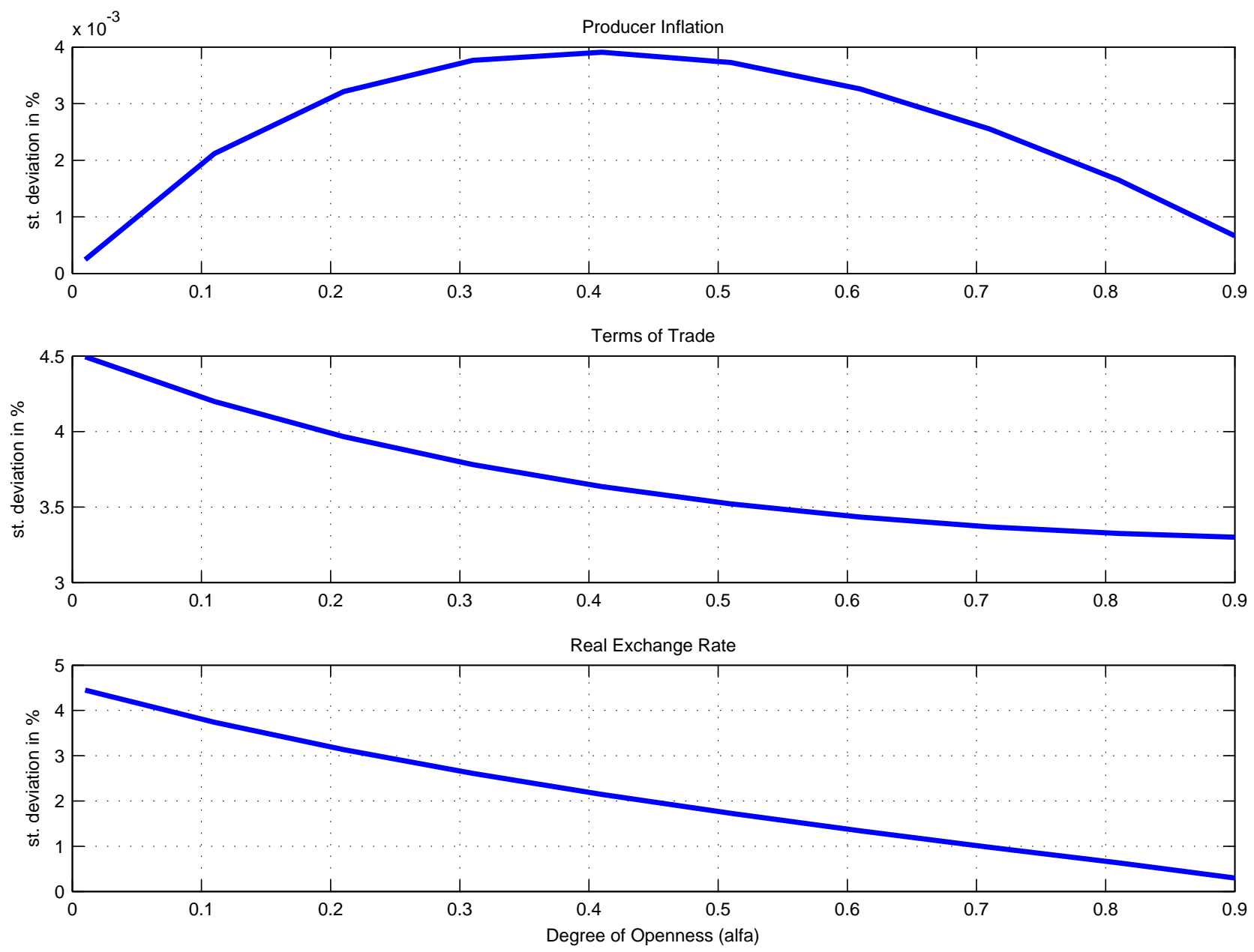